This item was submitted to Loughborough's Research Repository by the author.

Items in Figshare are protected by copyright, with all rights reserved, unless otherwise indicated.

\title{
Microstructure and texture development during solid consolidation recycling of Ti-6Al-4V
}

PLEASE CITE THE PUBLISHED VERSION

https://doi.org/10.1016/j.matchar.2018.10.020

PUBLISHER

(C) Elsevier

VERSION

AM (Accepted Manuscript)

\section{PUBLISHER STATEMENT}

This paper was accepted for publication in the journal Materials Characterization and the definitive published version is available at https://doi.org/10.1016/j.matchar.2018.10.020.

LICENCE

CC BY-NC-ND 4.0

\section{REPOSITORY RECORD}

Shi, Qi, Yau Tse, and Rebecca Higginson. 2018. "Microstructure and Texture Development During Solid Consolidation Recycling of Ti-6al-4v". figshare. https://hdl.handle.net/2134/36264. 


\title{
Microstructure and Texture Development during Solid Consolidation Recycling of Ti-6Al-4V
}

\author{
Q. Shi ${ }^{a, b}$, Y. Y. Tse ${ }^{b *}$ R. L. Higginson ${ }^{b}$ \\ a Guangdong Institute of Materials and Processing, Guangzhou, 510650 \\ ${ }^{b}$ Department of Materials, Loughborough University, Loughborough, United Kingdom \\ ※Corresponding author: Y. Y. Tse: Phone number: +441509223221; \\ Email: y.tse@lboro.ac.uk; Postal address: Department of Materials, Loughborough University, \\ Loughborough, United Kingdom, LE11 3TU.

\begin{abstract}
Ti-6Al-4V machining chips were recycled using equal channel angular pressing (ECAP). The microstructural and texture evolution of the recycled Ti-6Al-4V have been investigated using scanning electron microscopy, electron backscattered diffraction and transmission electron microscopy. For samples consolidated at $500{ }^{\circ} \mathrm{C}$ with a back-pressure of $100 \mathrm{MPa}$, the as-pressed density reached up to $99.9 \%$ after 8 passes. Pronounced grain refinement was also observed with increasing number of passes. The morphology of the grains has been changed from elongated and coarse to equiaxed and ultrafine as the number of passes increases. Strong textures were also introduced during multiple passes via $B_{c}$ route. Texture has been developed with basal planes parallel to the inclination direction which is at $21^{\circ}$ of the extrusion direction. After 4 and 8 passes, basal planes were rotated towards the transverse direction. No oxide can be detected at the chip-chip boundaries when the Ti-Al-4V machining chips was consolidated at $500{ }^{\circ} \mathrm{C}$. When the sample was processed at $550{ }^{\circ} \mathrm{C}$, significant grain growth and clear oxide layers at the chip-chip interface were observed. In addition, the c-axis were rotated towards the longitudinal direction due to the non-basal slip activity. TEM observation revealed the $\left\langle\vec{a}+\vec{c}>\right.$ dislocations presence in the $550{ }^{\circ} \mathrm{C}$ ECAP-processed sample.
\end{abstract}


Keywords: Ti-6Al-4V; Microstructure; Texture evolution; Low temperature solid consolidation recycling, Equal channel angular pressing

\section{Introduction}

Ti-6Al-4V is widely used in aerospace and biomedical applications due to its high specific strength, anti-corrosion property and bio-compatibility [1-3]. However, the relatively high price of Ti-6Al-4V alloy limits its broader applications. Traditional manufacture process of Ti-6Al-4V parts usually involves large amount of machining leading to substantial material waste. Conventional recycling methods involve re-melting and re-casting, which are high energy consumption processes. Recently, solid-state recycling with severe plastic deformation (SPD) process has been proposed as an energy-saving method for recycling various metallic machining chips mainly for softer metals and alloys, such as Mg alloys ${ }^{[4 ; 5]}$, Al alloys ${ }^{[6 ; 7]}$ and pure $\mathrm{Ti}^{[8]}$. In addition, SPD, such as equal channel angular pressing (ECAP) recycling has also been reported successfully demonstrated in harder alloys system, for example Ti-6AI-4V [9-12]. The ECAP recycled product can achieve 99.0\% density without any post processing ${ }^{[11]}$.

ECAP is a well-established SPD method to produce ultrafine grained bulk materials ${ }^{[13 ; 14]}$. During ECAP, simple shear deformation occurs in a narrow region at the intersecting plane of the inlet and outlet channels ${ }^{[15]}$, as marked as shear zone in Fig. 1. Since the sample is pressed through a die with the cross-sectional dimension unchanged, very large accumulative strain is possible to be imposed via repetitive passes. In this way, significant grain refinement and strong texture can be introduced. Both microstructure and crystallographic texture evolution strongly depend on the ECAP process parameters (e.g. prescribed processing route, temperature and number of passes) [16-19]. 
Studies have shown that texture has pronounced influence on mechanical properties, especially for hexagonal close packed (HCP) materials due to the anisotropy ${ }^{[20-23]}$, i.e. the mechanical properties of materials vary significantly with the loading directions. Several studies have been made on the microstructure and texture evolution of bulk ECAP-processed pure Ti alloys [24-27] and a few on Ti-6Al-4V [28]. The evolution of the texture of ECAP-processed pure Ti was reported to be originated mainly from twinning in the first pass at the processing temperature of $350{ }^{\circ} \mathrm{C}$ [29]. However, in the subsequent passes, the twinning was suppressed and the deformation was mainly accommodated by dislocation slips. Nevertheless, the active slip system during deformation in Ti-6Al-4V was under controversy in ECAP process: it was either depending on the specific route at the processing temperature of $350^{\circ} \mathrm{C}{ }^{[29]}$ or predominantly basal slip irrespective of routes at the ECAP temperature of $400{ }^{\circ} \mathrm{C}{ }^{[30]}$. Very limited works have been reported for the texture evolution of ECAP-processed Ti-6Al-4V. Due to the addition of $\mathrm{Al}$, it was expected that the twinning activity would be minimised in Ti-6Al-4V [31]. The current study revealed the possibility of producing bulk Ti-6AI-4V directly from machining chips at moderate temperature with refined grain structure. The microstructure evolution such as grain size and texture of the ECAP recycled Ti-6Al-4V after multiple passes (1, 2, 4 and 8 passes) and at different temperatures $\left(500^{\circ} \mathrm{C}\right.$ and $\left.550^{\circ} \mathrm{C}\right)$ will be discussed in this paper.

\section{Experimental materials and procedure}

The raw material used in this investigation was machining chips from a Ti-6Al-4V round bar with a diameter of $80 \mathrm{~mm}{ }^{[32]}$. In order to avoid contamination, coolant and lubricant were not used during the machining process. The machining chips were of $\sim 180 \mu \mathrm{m}$ thickness and saw-tooth shaped. According to our previous study, the machining chips consisted of the 
lamellar microstructure inherited from the bulk Ti-6Al-4V and primary shear zones induced during machining ${ }^{[11]}$. The detailed microstructure characterization of the initial machining chips has been reported elsewhere ${ }^{[11]}$.

Before ECAP, Ti-6AI-4V chips were pre-compacted into cylindrical bars with a diameter of $10 \mathrm{~mm}$ and a length of $\sim 70 \mathrm{~mm}$ by a hydraulic press and then wrapped with Al foil. The wrapped and pre-compacted specimens were subjected to ECAP via route $\mathrm{Bc}$ up to 8 passes at the temperature of $500{ }^{\circ} \mathrm{C}$ accompanied with a back-pressure of $100 \mathrm{MPa}$. In addition, samples pressed with a back-pressure of $250 \mathrm{MPa}$ at temperatures of $500{ }^{\circ} \mathrm{C}$ and $550{ }^{\circ} \mathrm{C}$ for a single pass were used for comparison. The pressing speed was also kept constant at $4 \mathrm{~mm} / \mathrm{min}$, and molybdenum disulphide $\left(\mathrm{MoS}_{2}\right)$ was used as lubricant in the ECAP channels. The ECAP die has an angle $(\phi)$ of $90^{\circ}$ between two channels and a relief angle $(\psi)$ of $\sim 36^{\circ}$ at the intersection, as shown in Fig. 1. This design gives a shear strain of $\sim 1$ after each passage through the die.

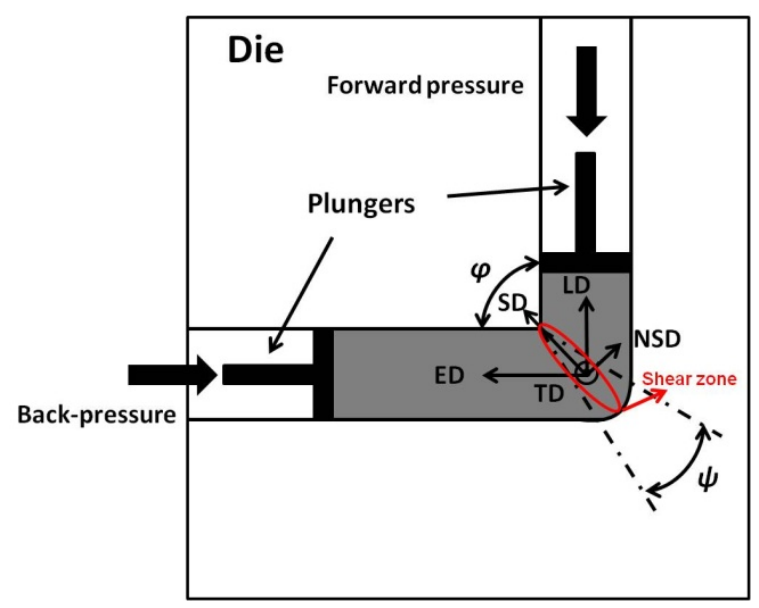

Fig. 1 Schematic cross section of the ECAP die, for which $\phi$ and $\psi$ equal to $90^{\circ}$ and $\sim 36^{\circ}$, respectively. The extrusion direction (ED), longitudinal direction (LD), transverse direction (TD), shear direction (SD) and normal to shear direction (NSD) of the ECAP process are also indicated.

Specimens for TEM examination were mechanically ground to a thickness of 100 $\mu \mathrm{m}$, and then $\mathrm{Ar}^{+}$ion milled for perforation. TEM images and 
corresponding selected area diffraction (SAD) patterns were obtained in a JEOL 2000FX operated at $200 \mathrm{kV}$.

The texture of the LD-ED plane (as shown in Fig. 1) was measured by a Carl Zeiss (LEO) 1530VP field emission gun (FEG) scanning electron microscope (SEM) fitted with a HKL Nordlys F high speed electron backscatter diffraction (EBSD) camera. The EBSD scans were done at an acceleration voltage of 20 $\mathrm{kV}$ with a $0.2 \mu \mathrm{m}$ step size and scan area of $100 \times 100 \mu \mathrm{m}$. The coordinate systems of the as-pressed specimen extrusion direction (ED), longitudinal direction (LD) and shear direction (SD) is shown in Fig. 2(a). It should be noted that the shear direction is $45^{\circ}$ to the longitudinal direction when the relief angle $\psi$ of the die is $0^{\circ}$. In the current die, $\psi$ is of $36^{\circ}$, therefore the shear direction is of $\sim 69^{\circ}$ to the longitudinal direction. The relative directions used in pole figures are shown in Fig. 2 (b) with direction normal to the shear direction (NSD), inclination direction (ID) and normal to inclination direction (NID) added to facilitate the texture description in the discussion section.

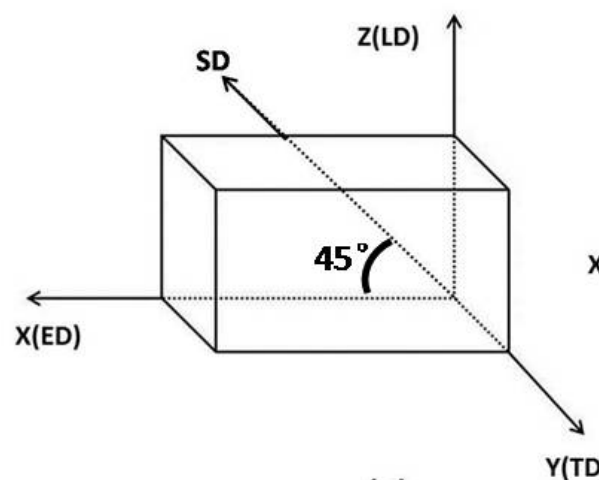

(a)

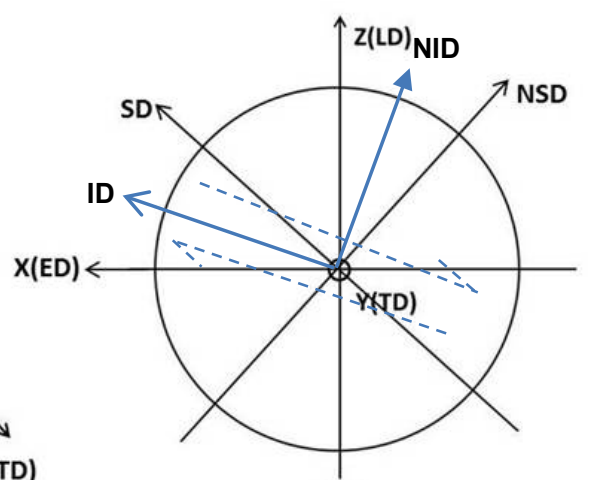

(b)

Fig. 2 (a) The coordinate system of as-pressed specimen, and (b) the reference coordinate system used in the pole figures, the dotted line and arrows indicating the shear directions of the current die design.

2. Experimental results and discussions

2.1 Effect of number of passes on microstructural and texture formation of recycled Ti-6Al-4V 
The microstructure feature was firstly illustrated by optical microscopy. Fig. 3a shows an optical micrograph of a recycled Ti-6Al-4V after single pass. It indicates that the chips inclined at $\sim 21^{\circ}$ with respect to the ED after one pass of the ECAP process, which is defined as the inclination direction (ID) in this study. The inclination direction of the chips with respect to the ED is near the theoretical shear flow line (i.e. the shear direction SD) which is about $21^{\circ}$ to the ED for a die with $\phi=90^{\circ}$ and $\psi=36^{\circ}{ }^{[33]}$ and it also agreed with the the experimental results presented elsewhere [30; 34; 35]. The inclination angle remains unchanged in the subsequent passes when the samples are processed with route $\mathrm{Bc}$ as shown in Fig $3 \mathrm{~b}$. The inclination angle is still $\sim 21^{\circ}$ after four passes.

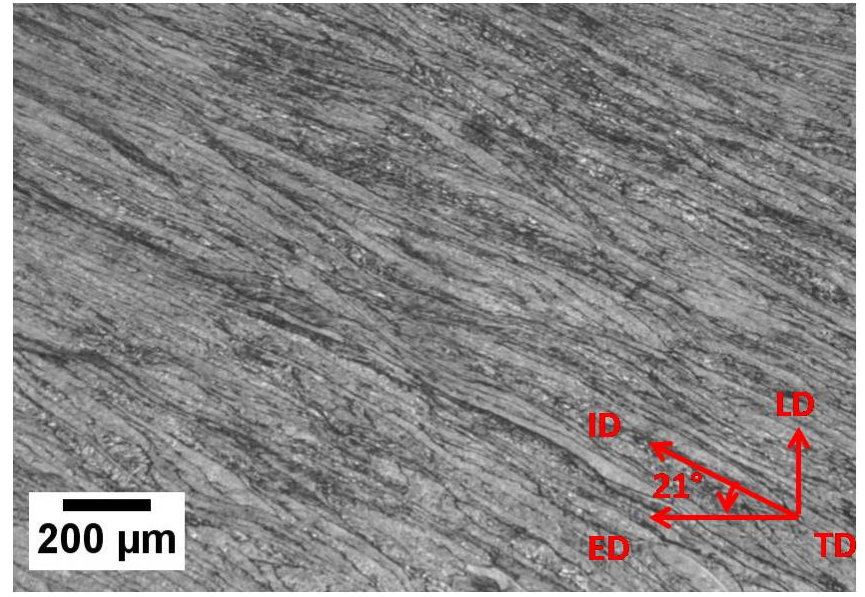

(a)

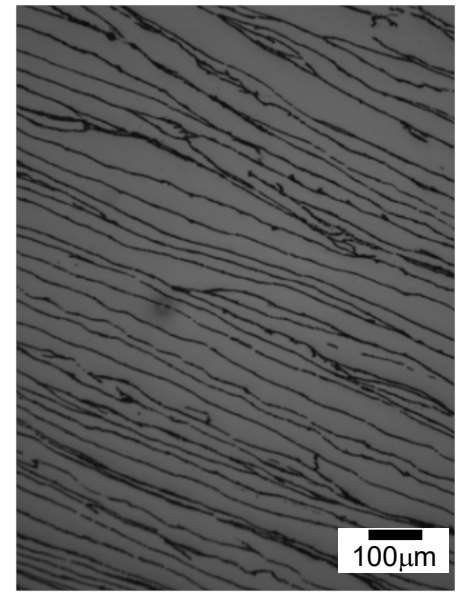

(b)

Fig. 3 Optical micrograph showing the Ti-6Al-4V chips after a) the first pass, b) the fourth pass. Chips are orientated at an inclination angle of $\sim 21^{\circ}$ with respect to the $E D$ after the first and fourth pass.

Figs. 4 (a) to (d) illustrate the texture evolution of the recycled Ti-6Al-4V after 1 , 2, 4 and 8 ECAP passes in $\{0002\}$ and $\{10 \overline{1} 0\}$ pole figures. To facilitate the discussion, the ideal fibre texture identified by Beausir et al. ${ }^{[36]}$ is shown in Fig. 4(e). The five ideal shear texture components $\left(P, B, Y, C_{1}\right.$ and $\left.C_{2}\right)$ have been referred to in the analysis for HCP crystals under simple shear, for example Ti alloys ${ }^{[30 ; 37-39]}$, although it is obtained from pure magnesium ${ }^{[36 ; 40]}$. 
As shown in Fig. 4(a), the basal poles were titled towards the direction inclining an angle of $\sim 21^{\circ}$ with the LD. This implies that the basal plane was almost aligned with the ID of ECAP. As evident by the $\{10 \overline{1} 0\}$ pole figure, grain orientation with $<10 \overline{1} 0>$ directions parallel to the ID is formed after one pass, and the development of three clusters at an angle of $\sim 60^{\circ}$ interval as shown in the pole figure represent the crystallographic symmetry of $\{10 \overline{1} 0\}$ family of planes. A schematic diagram of HCP crystal representing the orientation with respect to the reference coordinate system is shown in Fig. 5. Comparing with the ideal fibres, it is apparent that the textures developed after the first pass are the $B$ fibre as indicated by both $\{0002\}$ and $\{10 \overline{1} 0\}$ pole figures; nevertheless, the basal and prismatic poles drifted from the ideal position (SD is $45^{\circ}$ from ED in the ideal case). This is likely because the die used in the current study had a corner angle of $\sim 36^{\circ}$, while the ideal textures were simulated using relief angle of $0^{\circ}[36]$. Although the applied back-pressure could facilitate to narrow the ECAP shear zone, the area of deformation still fanned out during processing. This fibre texture is typical in ECAP-processed bulk

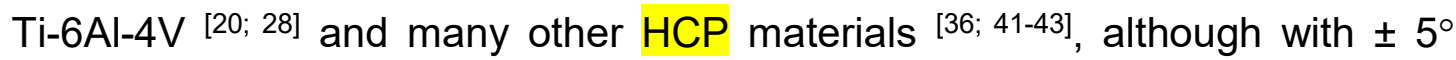
deviations of the inclination direction (ID) which is the imposed shear direction for the current die used in this study.

As the machining chips before ECAP were compacted similar to briquetting, all chips were assumed to be aggregated randomly, thus the initial texture is regarded weak. The strong $B$ fibre texture after the first pass as shown in Fig. 4(a) is mainly attributed to basal slip activity during ECAP, because basal slip $\{0001\}\langle 11 \overline{2} 0\rangle$ is the dominant deformation system in Ti-6Al-4V subjected to moderate-temperature ECAP [20]. This results in $\{0002\} / /$ ID texture. Although prismatic slip $\{10 \overline{1} 0\}\langle 11 \overline{2} 0\rangle$ is usually considered as the easiest slip system to be activated in $\alpha-\mathrm{Ti}$, during deformation the alloying elements like Al suppress the prismatic slip ${ }^{[44]}$. Furthermore, the critical resolved shear stress (CRSS) of 
basal slip reduces faster than prismatic slip with increasing temperature ${ }^{[28 ; 45]}$. In the current experimental conditions (ECAP-processed at $500^{\circ} \mathrm{C}$ ), the relative activity of basal slip is much higher than other deformation systems and it is agreed with the simulated results reported in the literature $[28,30]$. 

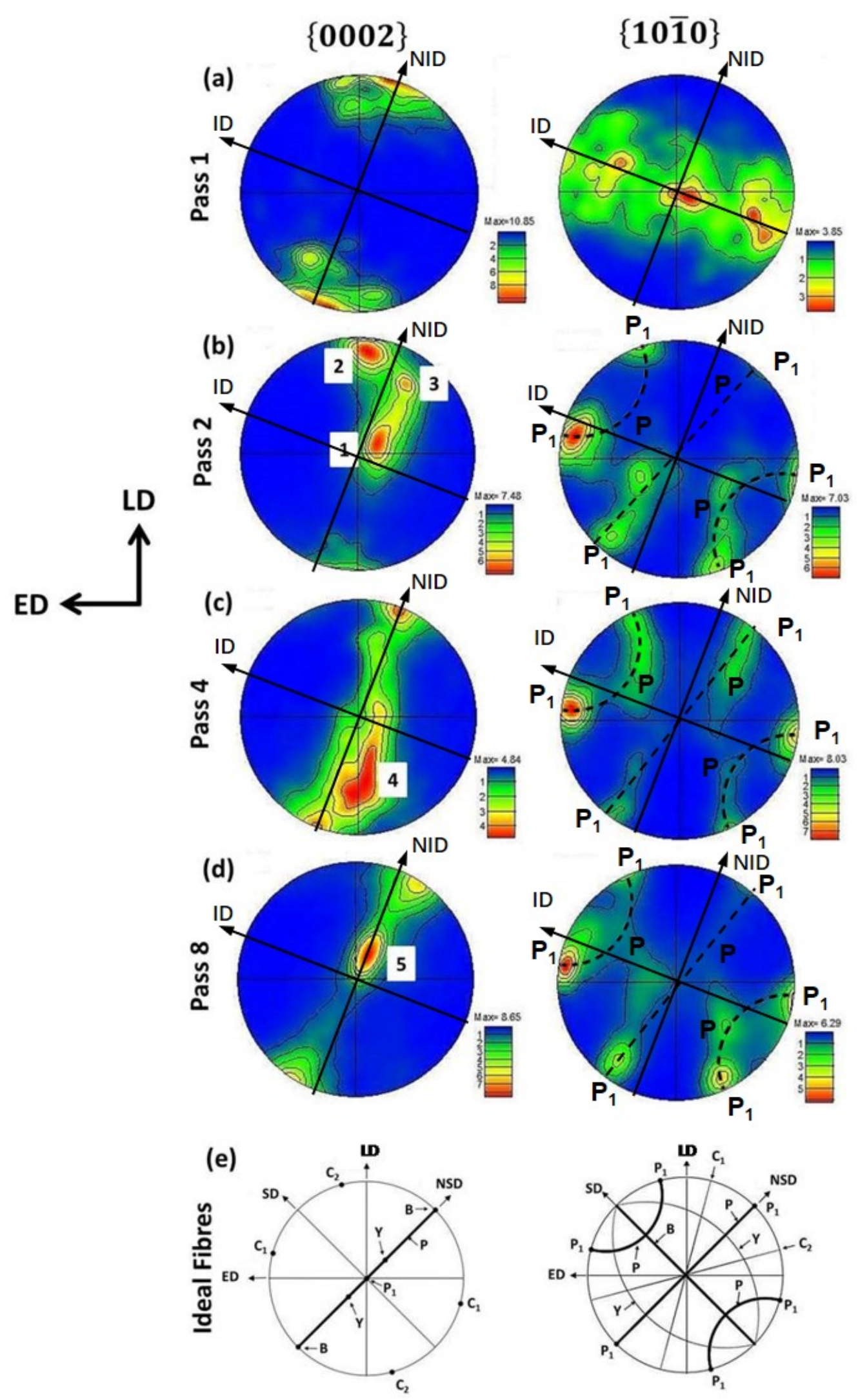

Fig. $4\{0002\}$ and $\{10 \overline{1} 0\}$ pole figures of Ti-6Al-4V recycled at $500{ }^{\circ} \mathrm{C}$ with a back-pressure of $100 \mathrm{MPa}$ after (a) 1, (b) 2, (c) 4,(d) 8 passes and (e) ideal fibres of Mg after ECAP with shear direction (SD) of $45^{\circ}$ about longitudinal direction (LD) (modified after ${ }^{[36]}$ ). 


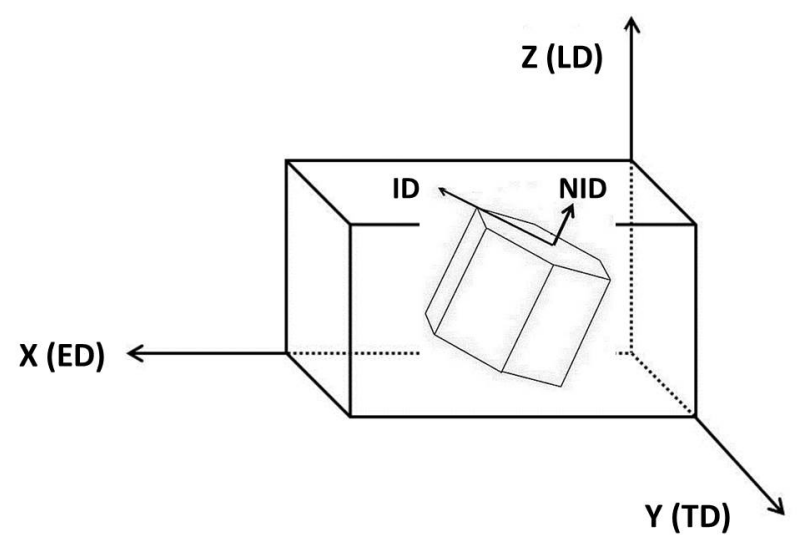

Fig. 5 Schematic diagram of $\alpha$-Ti crystal after the first pass showing the basal plane parallel to the inclination direction (ID)

After the second pass, it can be seen that the consequent texture exhibits three peaks in the $\{0002\}$ pole figure, as labelled in Fig. $4(b)$. In route $B_{c}$ the sample is rotated around the ED by $90^{\circ}$ in the same direct after each pass. The strong texture component labelled as peak 1 after two passes is the $P_{1}$ texture component, which is likely to inherit from the first pass, i.e. the $B$ texture developed after the first pass was rotated $90^{\circ}$ around ED, as illustrated in Fig. 6 , resulting the c-axis about $17^{\circ}$ away from TD. Peak 2 is attributed to the grain rotated by the imposed shear stress during the second pass, and hence a $B$ texture. Peak 3 (deviated from $P$ fibre texture) is formed due to the insufficient rotation of the $B$ texture after first pass (i.e. \{0002\}/ID) [37]. Comparing the texture of ECAP-processed pure Ti measured by XRD, both peaks 1 and 3 were observed [30;37]. The existence of peak 2 implies that for ECAP recycled Ti-6Al-4V chips, texture development differ to the bulk pure $\mathrm{Ti}$ is likely attribute to the different deformation mechanisms in Ti-6Al-4V [42]. The addition of alloying elements, constraint of chip boundaries and pressing temperature will affect the deformation mechanism. The corresponding $\{10 \overline{1} 0\}$ pole figure after two passes shows the presence of an incomplete P1 fibre texture, as indicated by dotted lines in Fig. 4(b). 
Fig. 4(c) shows that after 4 passes, the resulting $\{0002\}$ texture is dominant by the $B$ and $P$ fibre textures with $10-20^{\circ}$ spread. As shown in Fig. 4(d), it is observed that the basal texture after 8 passes is still dominated with the $B$ and $P$ fibres with a much smaller spread than that after 4 passes. The strongest texture, $P_{1}$ (peak 5) was found near the ideal position after 8 passes. Complementary with $\{10 \overline{1} 0\}$ pole figures, it is obvious that after 4 and 8 passes, $\mathrm{P}$ fibre textures are sharpened, although the positions are slightly rotated from the ideal locations. The evolution of the texture development shows that $B$ and $P$ textures are the most commonly occurred among the five ideal shear texture components after the second pass and these fibre textures are sharpened with the increase in number of passes.

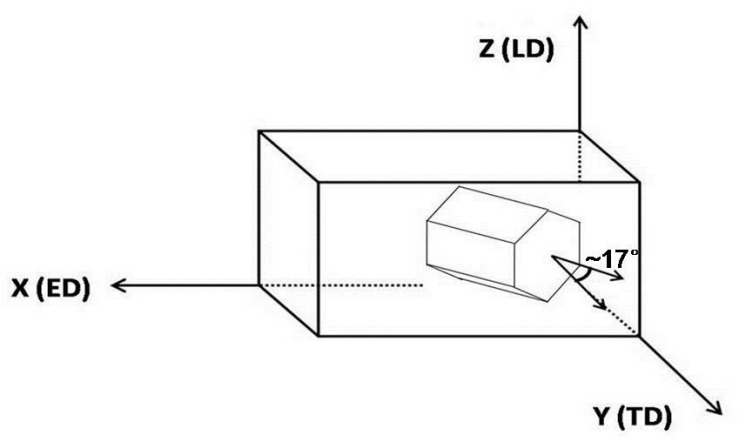

Fig. 6 Schematic diagram showing the rotation of $\alpha$-Ti crystal after 2 passes.

The most significant feature of the texture evolution after 4 and 8 passes is the rotation of $\mathrm{c}$-axis towards the TD ( $\mathrm{P}_{1}$ texture). This resembles the texture evolution of ECAP-processed pure $\mathrm{Ti}$ at $400{ }^{\circ} \mathrm{C}$ [30], although they only performed the ECAP experiments and simulations up to the 3rd pass and ignored the activity of twining in the simulation. For ECAP-processed pure $\mathrm{Ti}$ the twinning is an important mechanism to accommodate the deformation, especially in the first pass ${ }^{[29]}$, nonetheless, in the subsequent passes, the CRSS required to activate twinning is much larger than that required for activating dislocation slip in fine grain structure [29]. Eliminating of twinning 
activities in the simulation of pure Ti is more applicable in the case of Ti-6Al-4V, because the addition of alloying elements (e.g. Al) in Ti will suppress the twinning deformation mechanism $[31 ; 46 ; 47]$. The only observation of twinning in ECAP-processed Ti-6AI-4V was reported by Yapici et al. [28], where Ti-6Al-4V was pressed at $800{ }^{\circ} \mathrm{C}$ using route $\mathrm{A}$. Based on the present experimental results, the plastic deformation during the ECAP is expected to be majorly accommodated by dislocation slips.

The microstructures of samples after different numbers of passes are also shown in TEM micrographs (Fig. 7). The microstructure after one pass (Fig. 7(a)) contains chains of elongated grains, as indicated by the arrows. These deformed grains are originated from the lamellar structure (with size about $3 \mu \mathrm{m})$ of the initial machining chips as reported elsewhere [11]. As a result of the shearing during ECAP, the lamellae were refined and transverse grain boundaries formed due to the aggregation of dislocation cell walls. With further ECAP to 4 passes, as shown in Fig. 7(b), equiaxed grains with average size of $\sim 70 \mathrm{~nm}$ in diameter were started developing, but some elongated grains remained (as indicated by the arrows). After 8 passes, it is observed that there is no further grain refinement, however, the elongated grains were eliminated and the microstructure is dominated by nano-scaled and equiaxed grains. Similar results have been reported in our previous paper [11]."

The schematic diagram of grain refinement mechanism during multiple-pass ECAP is illustrated in Fig 8. The grains elongated at the first pass and more equiaxed grains will form with subsequent passes until reaching an equilibrium state. 


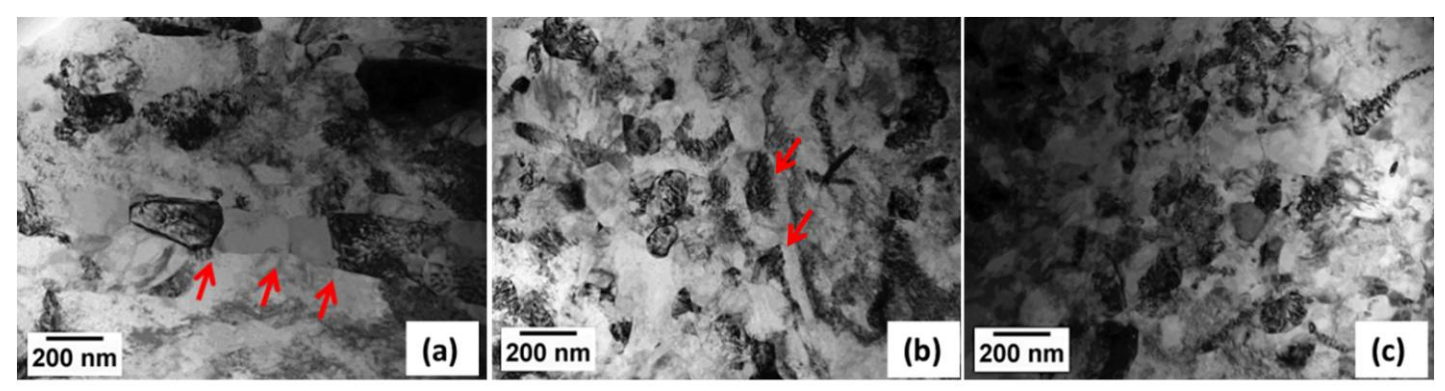

Fig. 7 TEM microstructure of recycled Ti-6Al-4V at $500{ }^{\circ} \mathrm{C}$ with a back-pressure of $100 \mathrm{MPa}$ for (a) 1, (b) 4 and (c) 8 passes.

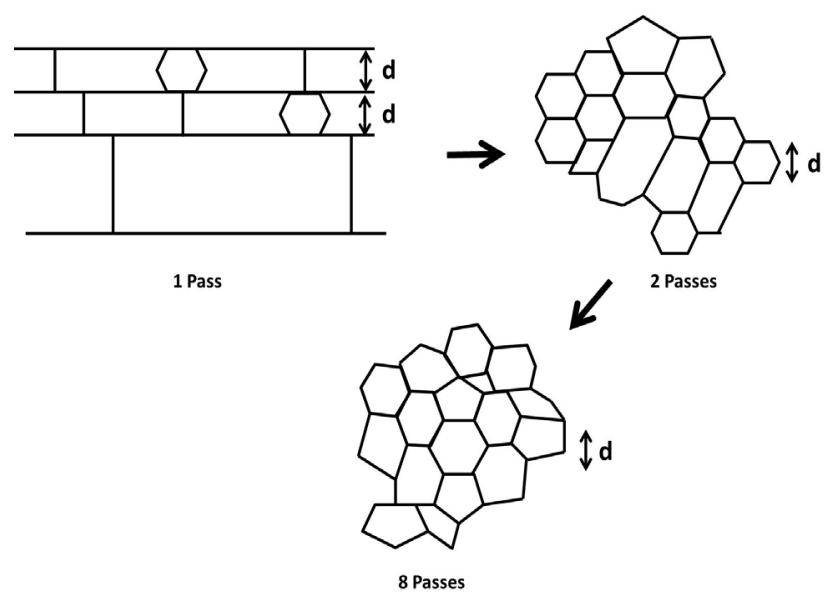

Fig. 8 Schematic diagram showing the grain refinement of recycled Ti-6Al-4V with the increase in number of ECAP passes. $d$ is denoted the smallest width $(\sim 70 \mathrm{~nm})$ of the lamella microstructure in the chips.

\subsection{Effect of pressing temperature on microstructure and texture formation of recycled Ti-6Al-4V}

Figs. 9(a) and (b) show the EBSD orientation maps of the samples after single pass with a back-pressure of $250 \mathrm{MPa}$ at $500^{\circ} \mathrm{C}$ and $550^{\circ} \mathrm{C}$, respectively. The sample processed at $500{ }^{\circ} \mathrm{C}$ had a relatively low EBSD indexing rate (Fig. 9(a)), because the quality EBSD patterns were poor in the regions consisting of ultrafine grains with high level of plastic strain. It is observed that the elongated grains were again parallel to the ID (Fig. 3). The increase in the processing temperature by $50{ }^{\circ} \mathrm{C}$ resulted in larger dynamic recovery and stress relief of the as-pressed sample, which has been indicated in the EBSD result with better indexing rate (Fig. 9(b)). In addition to ultrafine grains 
(marked by ovals, regions 1 and 2), larger and elongated grains were found (indicated by arrows), unlike those which processed at lower back pressure and temperature (Figs 8 and 9 (a)). The average diameter of the ultrafine grains in regions 1 and 2 is $\sim 250 \pm 60 \mathrm{~nm}$. The elongated grains have width ranged from $5-10 \mu \mathrm{m}$ and possess orientation change within a grain as indicated by the arrows in Fig 9. The misorientation profiles in Fig. 10(a) and (b) suggest the misorientation within the elongated grains in both samples pressed at different temperatures are less than $15^{\circ}$ indicating the existing of low angle grain boundaries in the deformed grain.
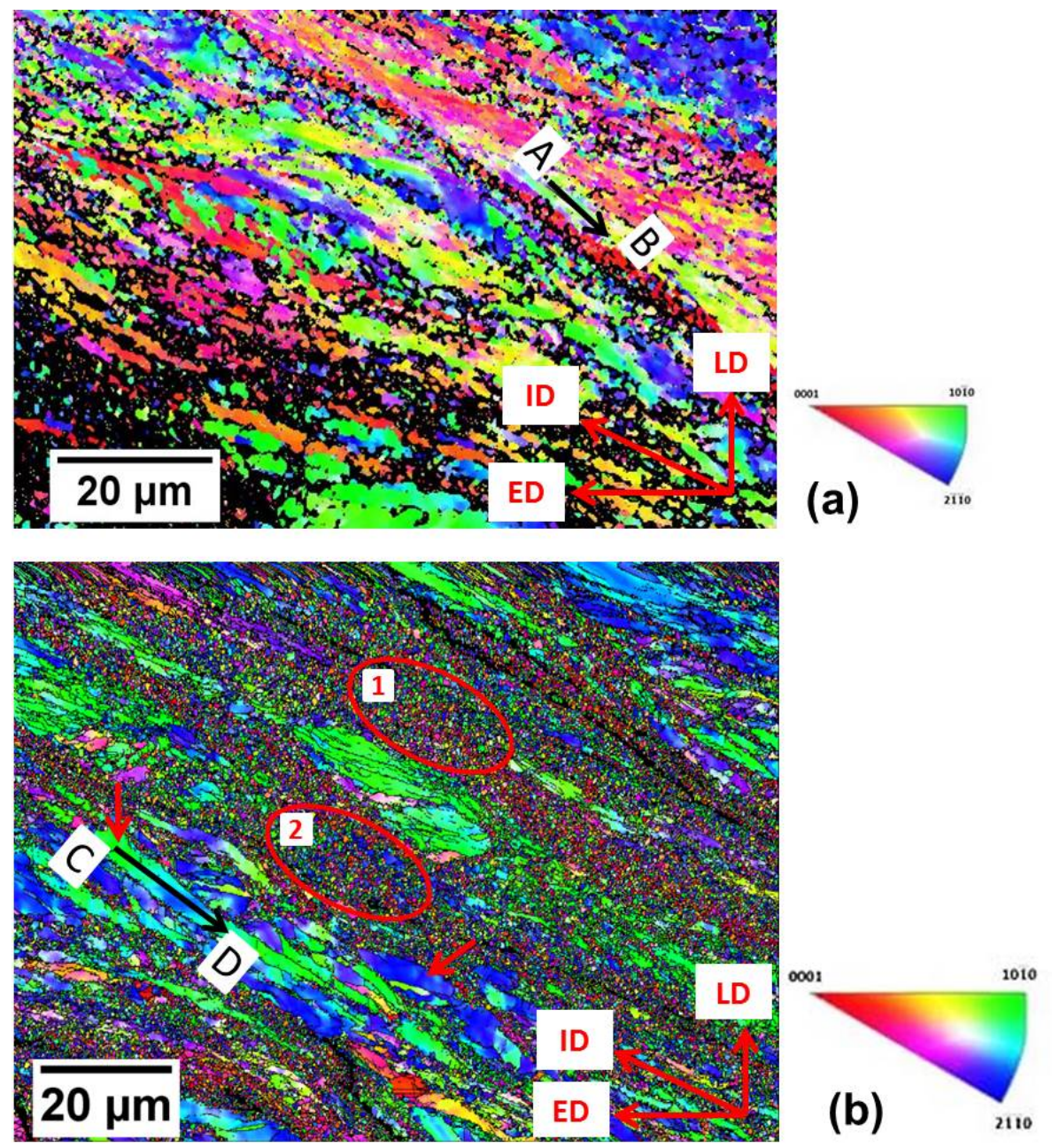

Fig. 9 EBSD orientation maps showing the microstructures of the recycled samples by single ECAP with a back-pressure of $250 \mathrm{MPa}$ at: (a) $500{ }^{\circ} \mathrm{C}$ and (b) $550{ }^{\circ} \mathrm{C}$. Post processing EBSD noise reduction was performed by extrapolating using the 5 nearest neighbours with a $5^{\circ}$ angular tolerance. 

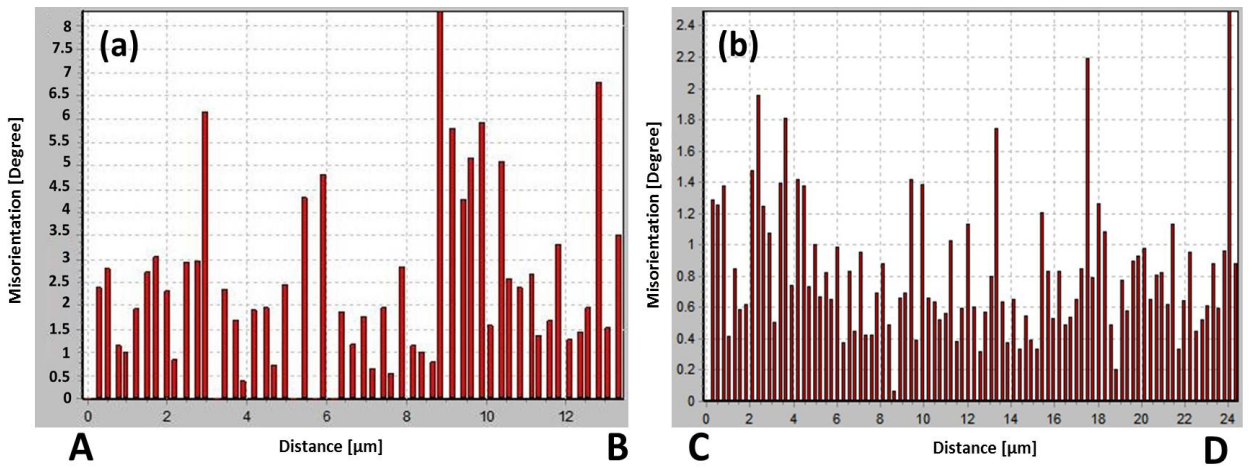

Fig. 10 Misorienation profiles measured along:(a) line $A B$ in EBSD map of sample pressed at $500{ }^{\circ} \mathrm{C}$ (Fig. 9(a)) and (b) line CD in EBSD map of sample pressed at $550{ }^{\circ} \mathrm{C}$ (Fig. 9(b)).

Due to the limited spatial resolution of EBSD, TEM was used to study the nano sized microstructures. In the samples processed at $500{ }^{\circ} \mathrm{C}$, the lamellar structure of the machining chips which was about 5 microns is refined down to lamellae with a width of $\sim 70 \mathrm{~nm}$, and transverse sub-grain boundaries are observed within the lamellae, as indicated by arrows in Fig. 11(a). The equiaxed grains with an average size of $\sim 70 \mathrm{~nm}$ are produced during the first pass (Fig. 11(b)). Such a bimodal structure in the single-pass sample has been reported in the previous research [11]. The coexisting of elongated and equiaxed $\alpha$ grains implies that the shearing strain during the first pass has not effectively refined the initial microstructure. Apart from the dominated $\alpha$ phase, lamellar $\beta$ phase was also identified, as shown in Fig. 11(c): The EDS analysis (Al: 3.04 wt.\%; V: 26.11 wt.\%) and corresponding SAD pattern confirms that the lamellar structure was $\beta$ phase. Compared to the initial $\beta$ phase (Fig. 11(d)), the grain size is decreased from $\sim 80 \mathrm{~nm}$ to $\sim 40 \mathrm{~nm}$. Similar result was obtained in bulk Ti-6Al-4V ECAP-processed at $600{ }^{\circ} \mathrm{C}$ to $800^{\circ} \mathrm{C}$, where the $\beta$ lamellae were thinned after the first pass by fragmentation [34]. 

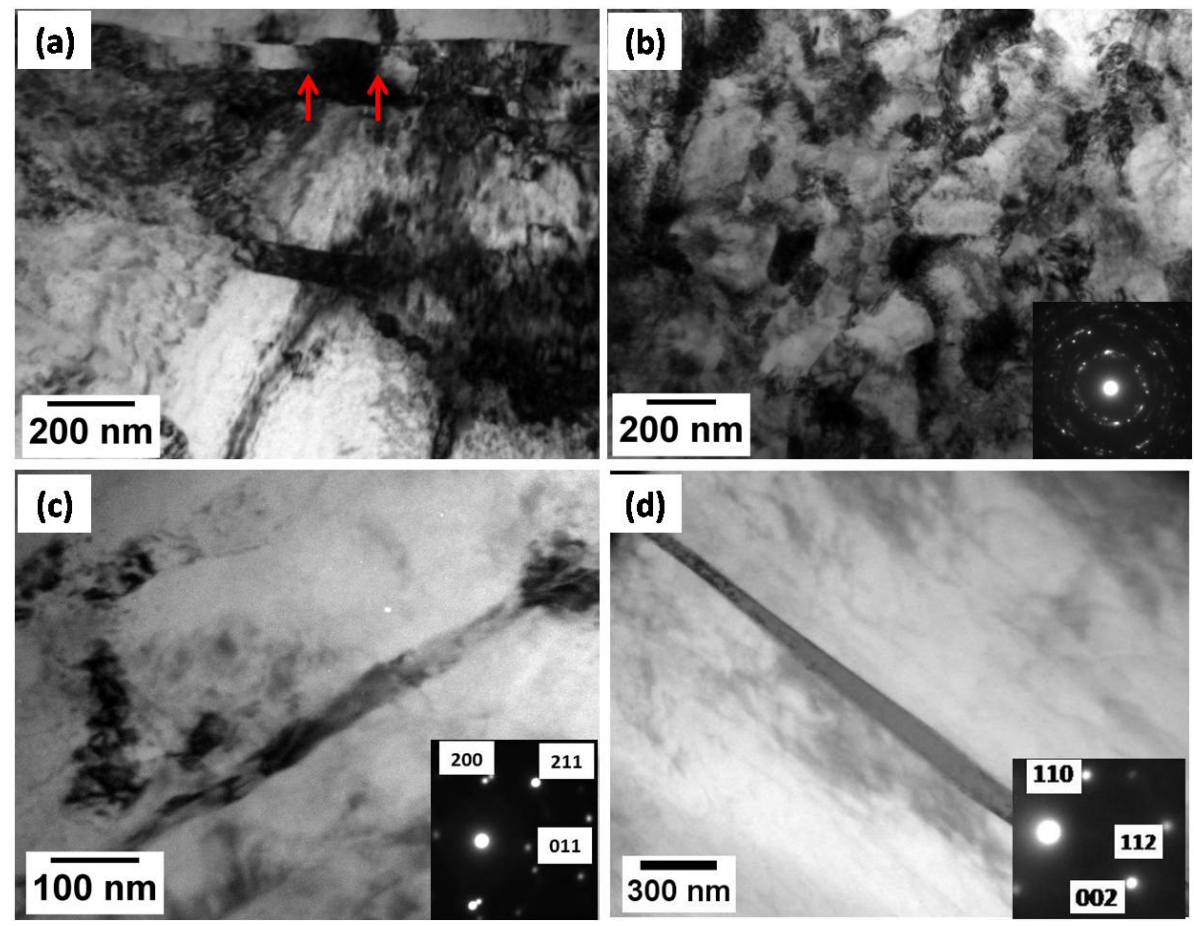

Fig. 11 Typical TEM microstructures developed during the single-pass ECAP at $500^{\circ} \mathrm{C}$ with a back-pressure of $250 \mathrm{MPa}$ : (a) lamellar structure, (b) equiaxed a grains with the inset showing the corresponding ring-shape SAD pattern, $(c$ and d) $\beta$ lamella with the inset of the corresponding $S A D$ pattern.
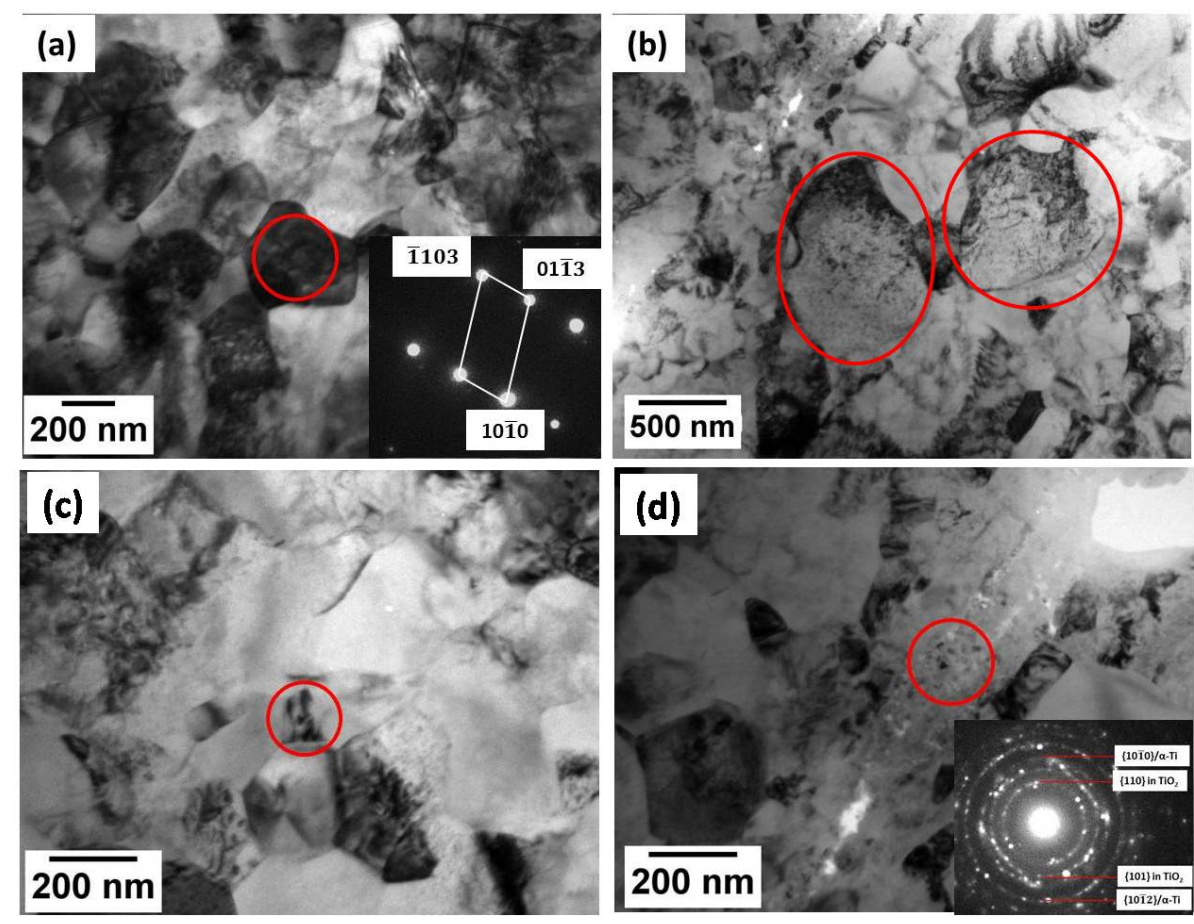

Fig. 12 TEM images of Ti-6Al-4V recycled by single ECAP at $550^{\circ} \mathrm{C}$ with a back-pressure of 250 MPa: (a) equiaxed a grains, (b) abnormally large a grains, (c) $\beta$ grain marked by the circle and (d) a chip/chip interface and corresponding SAD pattern. 
Table 1 Weight percentage of the chemical elements detected by EDS analysis at the chip/chip interface (marked by the circle in Fig. 12(d)) of the specimen processed at $550^{\circ} \mathrm{C}$.

\begin{tabular}{ccccc}
\hline Element & Ti & Al & V & O \\
\hline Concentration (wt.\%) & 58.5 & 5.7 & 2.6 & 33.2 \\
\hline
\end{tabular}

TEM micrographs show that the sample processed at $550^{\circ} \mathrm{C}$ has a relatively coarser and heterogeneous microstructure (Fig. 12). The grain size of the $\alpha$ phase was fallen into a wider range. Majority of the a grains have diameter of $\sim 300 \mathrm{~nm}$ (Fig. 12(a)), which is consistent with the EBSD results. In addition, some extra-large a grains with diameter of $\sim 600 \mathrm{~nm}$ were observed (Fig. 12(b)). The grain growth also occurred in $\beta$ phase as marked by the circle in Fig. 12(c): an equiaxed $\beta$ grain ( $V$ content of $\sim 26.17$ wt. $\%$ ) with a diameter of $\sim 100 \mathrm{~nm}$. The chip/chip interface is shown in Fig. 12(d) and the bright field image indicates a layer of finer structure which is not observable in the sample pressed at lower temperature $\left(500^{\circ} \mathrm{C}\right)$. The corresponding $S A D$ and EDS analysis (Table 1) suggest that is an oxide layer. The two innermost continuous rings of the SAD pattern are contributed by ultrafine grained $\mathrm{TiO}_{2}{ }^{[8]}$, and corresponding to the $\{110\}$ and $\{101\}$ rings of the tetragonal $\mathrm{TiO}_{2}$, as indicated in the inset of Fig. 12(d). The formation of oxide layers along the chip/chip boundaries or oxide particles within the matrix were reported in previous researches on solid state recycling of metallic chips $[5 ; 9 ; 48]$. The existence of oxide layers on machining chip surfaces was believed to be introduced during the machining process because of the substantial heat generation at the chip/tool interface ${ }^{[9]}$. However, in the current study, the oxide layer at the chip boundary was only observed in the sample processed at $550{ }^{\circ} \mathrm{C}$. The thickness of the naturally formed oxide layer on titanium alloys is less than $5 \mathrm{~nm}{ }^{[49]}$. Thus, it is plausible that the oxide layer in the samples pressed at $500{ }^{\circ} \mathrm{C}$ was too thin or has been fragmented to even finer oxide 
particles and those could not be detected by TEM EDS. The present result indicates thicker oxide layer was formed at the chip/chip interface when the sample was pressed at $550{ }^{\circ} \mathrm{C}$. The increase in temperature facilitated the formation of thicker oxide layer along the chip/chip interface. These oxide layers may be broken up into particles due to the severe plastic deformation during ECAP. The oxide dispersion strengthening (ODS) in ECAP-processed Mg and Ti alloys have been observed and partly responsible for the enhanced mechanical properties ${ }^{[5 ; 48]}$. The microhardness histograms of the samples ECAP-processed at $500{ }^{\circ} \mathrm{C}$ and $550{ }^{\circ} \mathrm{C}$ are plotted in Figs. 13(a) and (b), respectively. The red lines indicate the average hardness values. It is noticed that the degree of scattering for these two diagrams is almost identical; nonetheless, the sample pressed at $550{ }^{\circ} \mathrm{C}$ possessed a slightly higher average hardness than the sample pressed at $500{ }^{\circ} \mathrm{C}(384 \pm 21 \mathrm{HV}$ vs. $359 \pm 14$ HV). Considering the relatively coarser grains observed in the ECAP-processed sample at $550{ }^{\circ} \mathrm{C}$, the hardness measurement seems to be contradicted to the Hall-Petch relation. In this case, the hardness enhancement in the $550{ }^{\circ} \mathrm{C}$ ECAP-processed sample may be due to the strengthening by the fine oxide dispersed within the matrix [45].
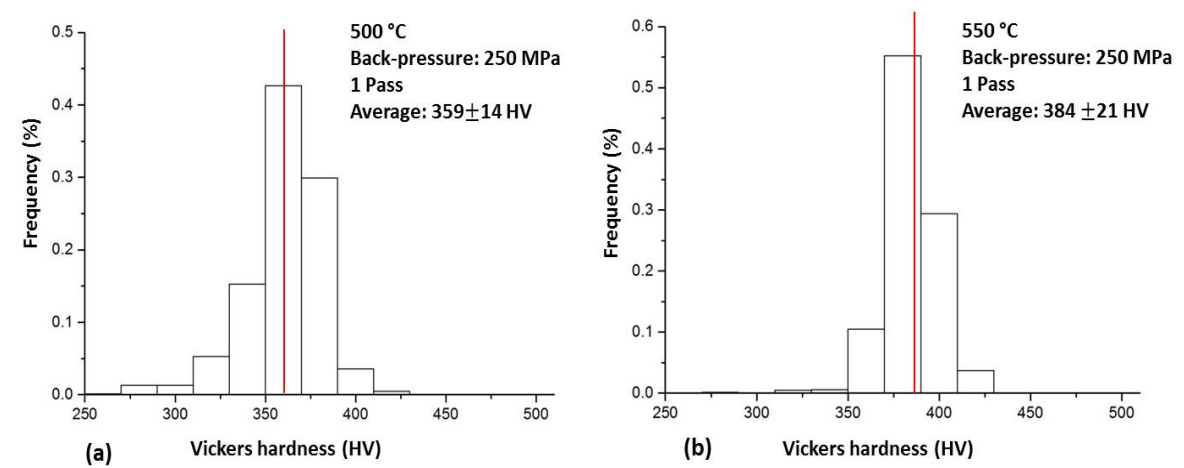

Fig. 13 The histograms showing the microhardness distributions of the samples after single ECAP pass with a back-pressure of $250 \mathrm{MPa}$ at (a) $500{ }^{\circ} \mathrm{C}$ and (b) $550{ }^{\circ} \mathrm{C}$.

Figs. $14(\mathrm{a})$ and (b) show $\{0002\}$ pole figures of recycled Ti-6AI-4V after single pass with a back-pressure of $250 \mathrm{MPa}$ at $500{ }^{\circ} \mathrm{C}$ and $550{ }^{\circ} \mathrm{C}$, respectively. 
Comparing the texture in Fig. 14(a) with the simulated ideal orientations (Fig. 4(e)), both $B$ and $P$ fibres were observed. In comparison to the single-pass recycled Ti-6AI-4V using a lower back-pressure of $100 \mathrm{MPa}$ (Fig. 4(a)), the texture components are rotated towards the LD. This may be due to the activation of the non-basal slip systems when the applied back-pressure increased [50; 51]. The increase in back-pressure leads to a narrow plastic deformation zone (PDZ) ${ }^{[52]}$, making the ECAP process close to the simple shear model. The shearing force can aggravate the deformation heating during ECAP [53], resulting in the reduced critical resolved shear stress (CRSS) for non-basal slip. In the sample processed at $550{ }^{\circ} \mathrm{C}$, the basal poles are rotated further towards the LD (Fig. 14(b)). It is because the CRSS for non-basal slip systems was further reduced with increasing processing temperature.

TEM observation provides evidence of the non-basal slip activity of the sample pressed at $550^{\circ} \mathrm{C}$. Fig. 15 shows the bright field images of dislocations under two beam conditions using a reflection of $\vec{g}=[0002]$. Because the dislocations (marked by arrows) are visible in this reflection condition, based on the invisibility criterion of $\vec{g} \cdot \vec{B}=0$, the dislocations must be non-basal $\langle\vec{a}+\vec{c}\rangle$ type with Burgers vector of $\left.\frac{1}{3}<11 \overline{2} 3\right]$.

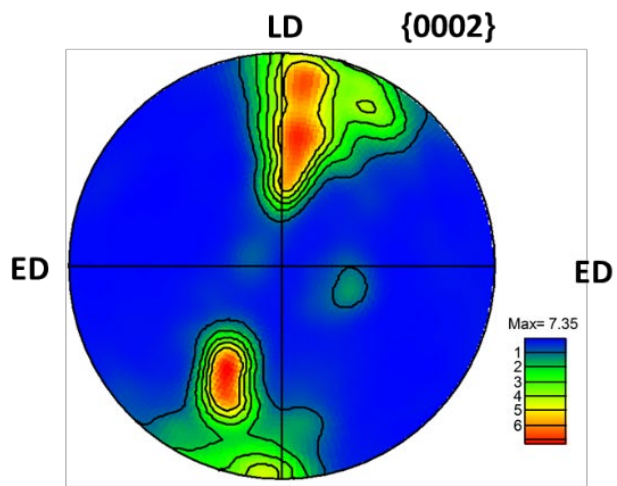

(a)

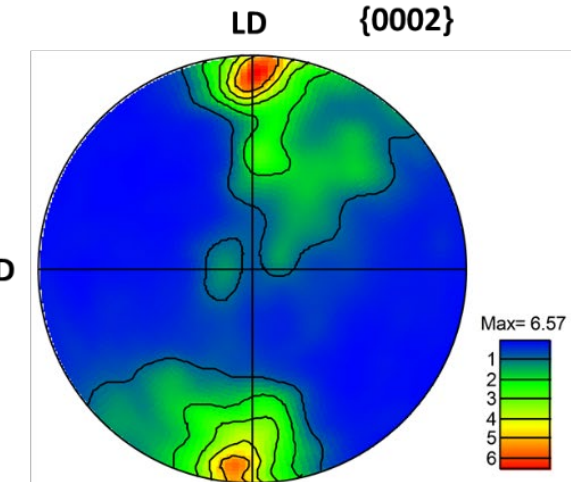

(b)

Fig. $14\{0002\}$ pole figures of recycled Ti-6Al-4V after one pass with a back-pressure of 250 $\mathrm{MPa}$ at temperatures of (a) $500^{\circ} \mathrm{C}$ and (b) $550^{\circ} \mathrm{C}$. 


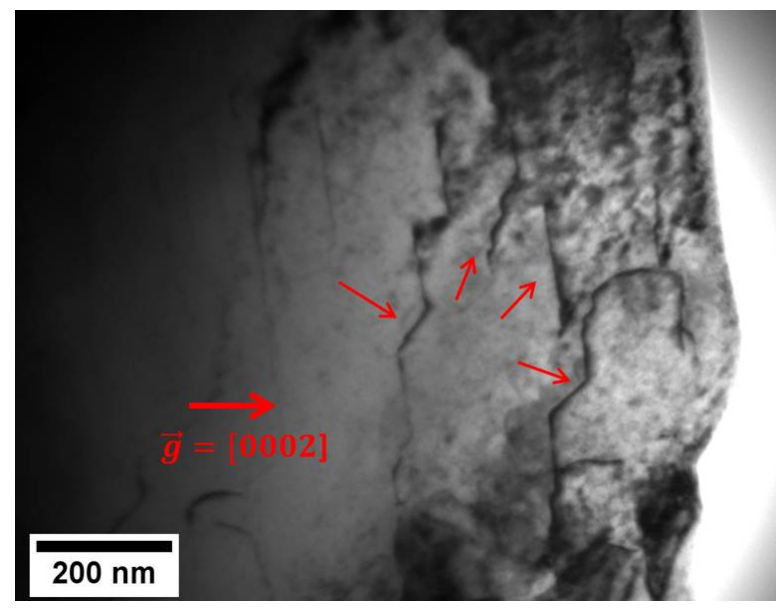

Fig. 15 TEM iamges of dislocations in the sample processed at $550{ }^{\circ} \mathrm{C}$ with a back-pressure of $250 \mathrm{MPa}$ after one pass, under two beam conditions using diffraction vector $\vec{g}=[0002]$.

\section{Conclusions}

In the present study, the microstructural and texture evolution of recycled Ti-6AI-4V by using ECAP were investigated after multiple passes and at different temperatures. At the processing temperature of $500{ }^{\circ} \mathrm{C}$, the microstructure is refined from elongated and coarser grains after a single pass to fully equiaxed and ultrafine grains after 8 passes. The shear deformation during ECAP leads to the formation of texture. The texture development after the first pass showed a strong $B$ texture. The further increase of passes to 4 and 8 makes the c-axis rotate towards the TD and NID with $10^{\circ}-20^{\circ}$ orientation spread due to the deformation by slips during the ECAP process using $B_{c}$ route. The increase in back pressure has no effect on the grain size and morphology of the ECAP processed samples, only the fibre texture is strengthened slightly with the increase in back pressure. The increase of the processing temperature by $50{ }^{\circ} \mathrm{C}$ resulted in the significant grain coarsening and the formation of oxide layer at the chip/chip interface. The fragmented oxide during ECAP may contribute to the improvement of microhardness. 
Additionally, the c-axis were observed to rotate towards the LD because of the activation of the non-basal slip resulting $\{0002\} / /$ LD texture.

\section{Acknowledgements:}

The authors acknowledge Dr Anish Roy and Dr Riaz Muhammad from School of Mechanical and Manufacturing Engineering in Loughborough University for providing machining chips. The authors thank Loughborough Materials Characterization Centre (LMCC) for electron microscopy supports.

The raw data required to reproduce these findings are available to download from [https://figshare.com/account/projects/35675/articles/6724634]

The processed data required to reproduce these findings are available to download from [https://figshare.com/account/projects/35675/articles/6724634]

\section{References}

[1] Boyer R, Welsch G, Collings E W. Materials Properties Handbook: Titanium Alloys[M]. ASM International, 1994.

[2] Boyer R R. An overview on the use of titanium in the aerospace industry[J]. Materials Science \& Engineering A, 1996, 213(1-2): 103-114.

[3] Geetha M, Singh A K, Asokamani R, et al. Ti based biomaterials, the ultimate choice for orthopaedic implants \&ndash; A review[J]. Progress in Materials Science, 2009, 54(3): 397-425.

[4] Tao Y, Zheng M Y, Xiao-Shi H U, et al. Recycling of AZ91 Mg alloy through consolidation of machined chips by extrusion and ECAP[J]. Transactions of Nonferrous Metals Society of China, 2010, 20(S2): s604-s607.

[5] Chino Y, Hoshika T, Mabuchi J S L M. Mechanical properties of AZ31 Mg alloy recycled by severe deformation[J]. Journal of Materials Research, 2006, 21(21): 754-760.

[6] Haase M, Ben Khalifa N, Tekkaya A E, et al. Improving mechanical properties of chip-based aluminum extrudates by integrated extrusion and equal channel angular pressing (iECAP)[J]. Materials Science and Engineering: A, 2012, 539: 194-204.

[7] Hyodo A, Bolfarini C, Ishikawa T T. Chemistry and tensile properties of a recycled AA7050 via spray forming and ECAP/E[J]. Mat Res, 2012, 15(5): 739-748.

[8] Luo P, Mcdonald D T, Palanisamy S, et al. Ultrafine-grained pure Ti recycled by equal channel angular pressing with high strength and good 
ductility[J]. Journal of Materials Processing Technology, 2013, 213(3): 469-476.

[9] Mcdonald D T, Luo P, Palanisamy S, et al. Ti-6Al-4V Recycled from Machining Chips by Equal Channel Angular Pressing[J]. Key Engineering Materials, 2012, 520: 295-300.

[10] Mcdonald D T, Lui E W, Palanisamy S, et al. Achieving Superior Strength and Ductility in Ti-6Al-4V Recycled from Machining Chips by Equal Channel Angular Pressing[J]. Metallurgical and Materials Transactions A, 2014, 45(9): 4089-4102.

[11] Shi Q, Tse $Y Y$, Higginson R L. Effects of processing parameters on relative density, microhardness and microstructure of recycled Ti-6Al-4V from machining chips produced by equal channel angular pressing[J]. Materials Science \& Engineering A, 2016, 651: 248-258.

[12] Lui E W, Palanisamy S, Dargusch M S, et al. Effects of chip conditions on the solid state recycling of Ti-6Al-4V machining chips[J]. Journal of Materials Processing Technology, 2016, 238: 297-304.

[13] Valiev R Z, Krasilnikov N A, Tsenev N K. Plastic deformation of alloys with submicron-grained structure[J]. Materials Science \& Engineering A, 1991, 137(C): 35-40.

[14] Valiev R Z, Estrin Y, Horita Z, et al. Producing Bulk Ultrafine-Grained Materials by Severe Plastic Deformation: Ten Years Later[J]. JOM, 2016, 68(4): 1216-1226.

[15] Segal V M. Materials processing by simple shear[J]. Materials Science \& Engineering A, 1995, 197(2): 157-164.

[16] Iwahashi Y, Horita Z, Nemoto M, et al. The process of grain refinement in equal-channel angular pressing[J]. Acta Materialia, 1998, 46(9): 3317-3331.

[17] Beyerlein I J, Tóth L S. Texture evolution in equal-channel angular extrusion[J]. Progress in Materials Science, 2009, 54(4): 427-510.

[18] Li S, Beyerlein I J, Alexander D J, et al. Texture evolution during multi-pass equal channel angular extrusion of copper: Neutron diffraction characterization and polycrystal modeling[J]. Acta Materialia, 2005, 53(7): 2111-2125.

[19] Biswas S, Brokmeier H G, Fundenberger J J, et al. Role of deformation temperature on the evolution and heterogeneity of texture during equal channel angular pressing of magnesium[J]. Materials Characterization, 2015, 102: 98-102.

[20] Yapici G G, Karaman I. Common trends in texture evolution of ultra-fine-grained hcp materials during equal channel angular extrusion[J]. Materials Science \& Engineering A, 2009, 503(1-2): 78-81.

[21] Bache M R, Evans W J. Impact of texture on mechanical properties in an advanced titanium alloy[J]. Materials Science \& Engineering A, 2001, s 319-321(00): 409-414. 
[22] Peters M, Gysler A, Lütjering G. Influence of texture on fatigue properties of Ti-6Al-4V[J]. Metallurgical and Materials Transactions A, 1984, 15(8): 1597-1605.

[23] Kohzu M, Hironaka T, Nakatsuka S, et al. Effect of Texture of AZ31 Magnesium Alloy Sheet on Mechanical Properties and Formability at High Strain Rate[J]. Journal of the Jstp, 2007, 48(4): 764-768.

[24] Meredith C S, Khan A S. The microstructural evolution and thermo-mechanical behavior of UFG Ti processed via equal channel angular pressing[J]. Journal of Materials Processing Technology, 2011, 219(8): 257-270.

[25] Jäger A, Gärtnerova V, Tesař K. Microstructure and anisotropy of the mechanical properties in commercially pure titanium after equal channel angular pressing with back pressure at room temperature[J]. Materials Science \& Engineering $A, 2015,644$ : 114-120.

[26] Rodriguez-Calvillo P, Cabrera J M. Microstructure and mechanical properties of a commercially pure Ti processed by warm equal channel angular pressing[J]. Materials Science \& Engineering A, 2015, 625: 311-320. [27] Wang L, Wang Y C, Zhilyaev A P, et al. Microstructure and texture evolution in ultrafine-grained pure Ti processed by equal-channel angular pressing with subsequent dynamic compression[J]. Scripta Materialia, 2014, 77(8): 33-36.

[28] Yapici G G, Karaman I, Luo Z P. Mechanical twinning and texture evolution in severely deformed Ti-6AI-4V at high temperatures[J]. Acta Materialia, 2006, 54(14): 3755-3771.

[29] Shin D H, Kim I, Kim J, et al. Microstructure development during equal-channel angular pressing of titanium[J]. Acta Materialia, 2003, 51(4): 983-996.

[30] Suwas S, Beausir B, Tóth L S, et al. Texture evolution in commercially pure titanium after warm equal channel angular extrusion[J]. Acta Materialia, 2010, 59(3): 1121-1133.

[31] Williams J C, Baggerly R G, Paton N E. Deformation behavior of HCP Ti-Al alloy single crystals[J]. Metallurgical and Materials Transactions A, 2002, 33(3): 837-850.

[32] Shi Q, Tse Y Y, Muhammad R, et al. Effect of Machining on Shear-Zone Microstructure in Ti-15V-3Cr-3Al-3Sn: Conventional and Ultrasonically Assisted Turning[J]. Journal of Materials Engineering and Performance, 2016, 25(9): 3766-3773.

[33] Wu S D. Nature of shear flow lines in equal-channel angular-pressed metals and alloys[J]. Philosophical Magazine Letters, 2007, 87(10): 735-741. [34] Yapici G G, Karaman I, Luo Z P, et al. Microstructure and mechanical properties of severely deformed powder processed Ti-6Al-4V using equal channel angular extrusion[J]. Scripta Materialia, 2003, 49(10): 1021-1027. 
[35] Segal V M, Hartwig K T, Goforth R E. In situ composites processed by simple shear[J]. Materials Science \& Engineering A, 1997, 224(96): 107-115. [36] Beausir B, Suwas S, Tóth L S, et al. Analysis of texture evolution in magnesium during equal channel angular extrusion[J]. Acta Materialia, 2008, 56(2): 200-214.

[37] Meredith C S, Khan A S. Texture evolution and anisotropy in the thermo-mechanical response of UFG Ti processed via equal channel angular pressing[J]. International Journal of Plasticity, 2012, 30-31(2): 202-217. [38] Suresh K S, Gurao N P, Satyaveer S D, et al. Effect of equal channel angular pressing on grain refinement and texture evolution in a biomedical alloy Ti 13Nb 13Zr[J]. Materials Characterization, 2013, 82(5): 73-85.

[39] Qarni M J, Sivaswamy G, Rosochowski A, et al. On the evolution of microstructure and texture in commercial purity titanium during multiple passes of incremental equal channel angular pressing (I-ECAP)[J]. Materials Science \& Engineering A, 2017, 699: 31-47.

[40] Beausir B, Tóth L S, Neale K W. Ideal orientations and persistence characteristics of hexagonal close packed crystals in simple shear[J]. Acta Materialia, 2007, 55(8): 2695-2705.

[41] Figueiredo R B, Beyerlein I J, Zhilyaev A P, et al. Evolution of texture in a magnesium alloy processed by ECAP through dies with different angles[J]. Materials Science \& Engineering A, 2010, 527(7-8): 1709-1718.

[42] Beyerlein I J, Field R D, Hartwig K T, et al. Texture development in two-pass ECAE-processed beryllium[J]. Journal of Materials Science, 2008, 43(23): 7465-7473.

[43] Al-Maharbi M, Karaman I, Beyerlein I J, et al. Microstructure, crystallographic texture, and plastic anisotropy evolution in an Mg alloy during equal channel angular extrusion processing[J]. Materials Science \& Engineering A, 2011, 528(25-26): 7616-7627.

[44] Sakai T, Fine M E. Plastic deformation of Ti-Al single crystals in prismatic slip $\lesssim[J]$. Acta Metallurgica, 1974, 22(11): 1359-1372.

[45] Kim S M, Kim J, Shin D H, et al. Microstructure development and segment formation during ECA pressing of Ti-6Al-4V alloy[J]. Scripta Materialia, 2004, 50(7): 927-930.

[46] Agnew S R, Mehrotra P, Lillo T M, et al. Texture evolution of five wrought magnesium alloys during route $A$ equal channel angular extrusion:

Experiments and simulations[J]. Acta Materialia, 2005, 53(11): 3135-3146.

[47] Conrad H. "Effect of Interstitial Solutes on the Strength and Ductility of Titanium,"[J]. Progress in Materials Science, 1981, 26(2-4): 123-403.

[48] Luo P, Xie H, Paladugu M, et al. Recycling of titanium machining chips by severe plastic deformation consolidation[J]. Journal of Materials Science, 2010, 45(17): 4606-4612. 
[49] Hertl C, Werner E, Thull R, et al. Oxygen diffusion hardening of $\mathrm{cp}$-titanium for biomedical applications[J]. Biomedical Materials, 2010, 5(5): 054104.

[50] Kang F, Liu J Q, Wang J T, et al. The effect of hydrostatic pressure on the activation of non-basal slip in a magnesium alloy[J]. Scripta Materialia, 2009, 61(8): 844-847.

[51] Kang F, Liu J Q, Wang J T, et al. Equal Channel Angular Pressing of a Mg-3Al-1Zn Alloy with Back Pressure[J]. Advanced Engineering Materials, 2010, 12(8): 730-734.

[52] Lapovok R. The Positive Role of Back-Pressure in Equal Channel Angular Extrusion[J]. Journal of Materials Science, 2006, 503-504(40): 37-44.

[53] Semiatin S L, Berbon P B, Langdon T G. Deformation heating and its effect on grain size evolution during equal channel angular extrusion[J].

Scripta Materialia, 2001, 44(1): 135-140. 